\title{
CVD Treatment of Carbon Fibers and Evaluation of Their Dispersion in CFRC
}

\author{
Chuang Wang1*, Bingliang Li1 ${ }^{1}$, Lei Peng1, Wenmin He1, Liping Zhao1, Kezhi Li² \\ ${ }^{1}$ Shaanxi Province Engineering Laboratory of High Performance Concrete, Shaanxi Railway Institute, Weinan, China \\ ${ }^{2}$ School of Materials Science and Engineering, Northwestern Polytechnical University, Xi'an, China \\ Email: *wangchuang1961@sina.com
}

How to cite this paper: Wang, C., Li, B.L., Peng, L., He, W.M., Zhao, L.P. and Li, K.Z. (2017) CVD Treatment of Carbon Fibers and Evaluation of Their Dispersion in CFRC. Materials Sciences and Applications, 8, 649-661.

https://doi.org/10.4236/msa.2017.88046

Received: July 15, 2017

Accepted: August 15, 2017

Published: August 18, 2017

Copyright $\odot 2017$ by authors and Scientific Research Publishing Inc. This work is licensed under the Creative Commons Attribution International License (CC BY 4.0).

http://creativecommons.org/licenses/by/4.0/

\begin{abstract}
Carbon-fiber-reinforced cement-based (CFRC) composites is a promising functional material which can be used both in the military and civil fields against electromagnetic interference. However, it is essential to make carbon fibers dispersed uniformly during the preparation of CFRC. In this work, short carbon fibers were treated through Chemical Vapor Deposition (CVD) process at high temperature between $900^{\circ} \mathrm{C}$ and $1200^{\circ} \mathrm{C}$ under the protection of diluted nitrogen gas $\mathrm{N}_{2}$ to modify the surface of carbon fibers to further strengthen the bonding between carbon fibers and cement matrix. Natural gas $\left(98 \% \mathrm{CH}_{4}\right)$ was used as a precursor. It was decomposed to produce an uneven layer of pyrocarbon that was deposited on the surface of carbon fibers. CVD-treated carbon fibers were pre-dispersed by using ultrasonic wave. Both hydroxyethyl cellulose (HEC) and silicon fume were used as dispersants and as admixtures. They helped CVD-treated carbon fibers distribute uniformly. The mass fraction of HEC was around $1.78 \%$ in the aqueous solution. Four methods, namely, the simulation experiment (SE) method, the scanning electron microscopy (SEM) method, the fresh mixture (FM) method, and the electrical resistivity measurement (ERM) method were, respectively, applied to evaluate fiber dispersion degree. Each method indicated its own advantages and disadvantages and it therefore catered for different conditions. Of the four evaluation methods, the SE method was the most convenient way to determine the pre-dispersion state prior to the preparation of CFRC composites. This method was helpful for predicting the subsequent dispersion state of carbon fibers in the cement matrix because it economized a large quantity of raw materials and time.
\end{abstract}

\section{Keywords}

Carbon Fiber, Chemical Vapor Deposition, Hydroxyethyl Cellulose, Dispersion 


\section{Introduction}

The commercialization of short carbon fiber-reinforced cement composites (CFRC) has become possible with the development of relatively low-cost, pitch-based carbon fibers in recent years [1] [2] [3]. Carbon fiber exhibits high elasticity, high modulus, less density, good electricity conductivity, and resistance to corrosion hence excellent reinforcement for composites. Reinforcement with carbon fibers can lead to great improvement in flexural strength and toughness, tensile performance, impact resistance and durability of cementitious materials [1] [3] [4]. In addition, there has been an increasing interest in use of CFRC as functional sensibility [1] [5] [6]. The effectiveness of the added fiber depends on the degree of fiber dispersion. Numerous previous works were focused on the improvement of fiber dispersion [7] [8] [9]. Electrical resistivity measurement has been used to assess the degree of steel fiber dispersion [1] [10] [11], but little has been reported on the comparison of different methods, especially dispersion of carbon fibers after Chemical Vapor Deposition (CVD) treatment.

Carbon fiber dispersion, which is a common topic, and usually difficult to cope with [1] [2] [3] [12], greatly influences the properties of CFRC especially when carbon fibers were surface treated by CVD method in a high temperature furnace $\left(900^{\circ} \mathrm{C}-1200^{\circ} \mathrm{C}\right)$.

In the present work, carbon fibers were surface treated at high temperature between $900^{\circ} \mathrm{C}$ and $1200^{\circ} \mathrm{C}$ under the protection of diluted nitrogen gas $\mathrm{N}_{2}$ to modify the surface of carbon fibers. On one hand, after carbon fibers are treated at high temperature by CVD, a thin lay of pyrocarbon will deposit unevenly on the surface of carbon fibers, forming a large number of grooves which are beneficial for the bonding between carbon fibers and cement matrix. On the other, active groups such as hydroxyl and carboxyl groups will be activated. Then, the treated fibers were dispersed under the synergistic action of a dispersant of hydroxyethyl cellulose (HEC) and an admixture of silicon fume. Four methods were applied to evaluate the dispersion degree of CVD-treated carbon fibers. They are the simulation experiment method (SE), the scanning electron microscope method (SEM), the fresh mixture method (FM), and the method of the electrical resistivity measurement (ERM), respectively. The four methods were experimentally validated and the characteristic of each method was illustrated.

\section{Experimental}

\subsection{Materials and Experimental Methods}

Carbon fibers used were PAN-based $5 \mathrm{~mm}$ in length provided by Jiyan Carbon Ltd. Co. (Jilin, China). Their mass fraction was $0.5 \%$ by weight of cement. The major properties are shown in Table 1. The matrix was $42.5 \mathrm{R}$ Portland cement with the execution standard GB175-1999 (Yaobo Cement Plant, Shaanxi, China). The dispersants used were hydroxyethyl cellulose (HEC) made in Shangdong with the viscosity of 30,000 Pa.s and silicon fume (Shanghai, 300 mesh, purity 
Table 1. Major parameters of short carbon fibers.

\begin{tabular}{ccccccc}
\hline Item & $\begin{array}{c}\text { Diameter } \\
(\mathrm{um})\end{array}$ & $\begin{array}{c}\text { Density } \\
\left(\mathrm{g} / \mathrm{cm}^{3}\right)\end{array}$ & $\begin{array}{c}\text { Strength } \\
(\mathrm{MPa})\end{array}$ & $\begin{array}{c}\text { Shear } \\
\text { strength } \\
(\mathrm{MPa})\end{array}$ & $\begin{array}{c}\text { Modulus } \\
(\mathrm{GPa})\end{array}$ & $\begin{array}{c}\text { Resistivity } \\
(\Omega / \mathrm{m})\end{array}$ \\
\hline Index & $7 \pm 0.2$ & $1.76 \pm 0.1$ & $2.5-3.0$ & 80 & $200-220$ & 310 \\
\hline
\end{tabular}

99.7\%). The mass fraction of HEC was in the amount of $0.6 \%$ by weight of cement. The water/cement ratio was 0.46 . Silica fume was used in the amount of $12 \%$ by weight of cement. Naphthalenesulfonate condensate (FDN), a solid water-reducing agent, was used in the amount of $1.0 \%$ by weight of cement. The defoamer was liquid tributyl phosphate (TBP) made in Wuhan. No coarse aggregate was added.

\subsection{CVD Surface Treatment of Carbon Fibers}

Short carbon fibers were rapped loosely with a piece of carbon cloth and placed in a middle sized deposition furnace for CVD processing. There were numerous small pores in the carbon cloth for the gas to pass through. The furnace was evacuated and no leakage was ensured. Natural gas $\left(98 \% \mathrm{CH}_{4}, 0.3 \% \mathrm{C}_{3} \mathrm{H}_{8}, 0.3 \%\right.$ $\mathrm{C}_{4} \mathrm{H}_{10}, 1 \% \mathrm{~N}_{2}, 0.4 \%$ other hydrocarbons) was used as a precursor to access into the furnace under the protection of diluted nitrogen gas $\mathrm{N}_{2}$ to avoid oxidation of carbon fibers at high temperature. The gas flow rate was controlled between 2 - 5 $\mathrm{m}^{3} / \mathrm{h}$.

The entire CVD process was conducted at ambient pressure. The manipulated temperature inside the furnace was kept between $900^{\circ} \mathrm{C}-1200^{\circ} \mathrm{C}$. Under this condition, the pyrolytic reaction took place inside the furnace. Methane was decomposed to generate pyrocarbon, which is gradually deposited on the surface of fibers. This is the typical CVD process [2] [13] [14]. The treatment time was 96 hours. Carbon fibers were observed under a SEM-JSM 6700F scanning electron microscope before and after treatment.

\subsection{Preparation of CFRC Specimens}

Short carbon fibers were placed into a $500 \mathrm{~mL}$ beaker with $200 \mathrm{~mL}$ water and immersed fully into water. The beaker was vibrated by ultrasonic wave for $30 \mathrm{~min}$ for pre-dispersion, during which a glass rod was used to stir the fibers intermittently. HEC was then added in for the promotion of dispersion of carbon fibers. The beaker was stirred by hand for $1 \mathrm{~min}$. Then, it was continuously vibrated for another $30 \mathrm{~min}$.

Two drops of TBP were added in to eliminate air bubbles in the solution. The mass fraction of HEC in the aqueous solution was controlled between 1.66 and $1.86 \%$. The temperature of the solution during vibration was kept around $45^{\circ} \mathrm{C}$. The power of the ultrasonic wave was $250 \mathrm{~W}$. A glass rod was used to stir the fibers intermittently to ensure the uniform dispersion of carbon fibers in the transparent, sticky solution. No breakage of carbon fibers occurred during the process of ultrasonic wave vibration. Now, a dispersion mixture was prepared. This was 
the first step for the subsequent preparation of CFRC samples.

Silicon fume, cement, and FDN were added in order very carefully into a J$160 \mathrm{~A}$ agitator with a flat beater. The mixture was stirred slowly for 30 seconds. Now, the prepared liquid in the first step was poured into the agitator and stirred for $3 \mathrm{~min}$. Eight pieces of samples were used every time to investigate the effect of mixing time on the fiber dispersion by the FM method.

To compare SEM and ERM methods, the mixture was poured into the $40 \times 40 \times$ $40 \mathrm{~mm}$ oiled molds. For each type of experiment, six specimens were tested. For SE method, two $200 \mathrm{~mL}$ glass beakers were prepared. Small amounts of fibers were added into water with HEC and without HEC, respectively, to observe fiber dispersion while and after stirring. After pouring the mixture into the moulds, an external vibrator was used to facilitate compaction and decrease the amount of air bubbles. The samples were then placed in a curing box and demolded after 24 hours and then allowed to cure in the curing box for 28 days inside which the temperature was kept around $22^{\circ} \mathrm{C}$. The relative humidity was over $92 \%$.

\section{Evaluation Methods of Carbon Fiber Dispersion}

\subsection{SE Method}

Short carbon fibers were initially placed in a $200 \mathrm{~mL}$ glass beaker. $100 \mathrm{~mL}$ water was added to ensure that fibers were completely submerged in the water. The beaker was vibrated by ultrasonic wave for $30 \mathrm{~min}$, during which the temperature of water keeps around $45^{\circ} \mathrm{C}$. HEC was added into the beaker and stirred by a glass rod. Then, the beaker was continuously vibrated by ultrasonic wave for another $30 \mathrm{~min}$. Those processes are the pre-dispersion of carbon fibers and they are very helpful for the uniform dispersion of carbon fibers in the subsequent preparation of CFRC samples.

In this pre-dispersion process, carbon fibers can be seen clearly through the glass. The dispersion degree can be evaluated intuitively by the simulation experiment (SE) method.

Pour the mixture onto a clean white enamel plate and spread it uniformly. Digital pictures were taken as shown in Figure 1 and the observed results were described in Table 2. It can be seen clearly from the photos that carbon fibers were not well dispersed in water without HEC (Figure 1(a)) whereas uniformly distributed with HEC (Figure 1(b)). Fibers in fascicules were apparently observed in the former photo.

In this experiment, the dispersion of carbon fibers, whether they are dispersed singly or not, can be well observed. It economizes a significant amount of raw materials such as expensive silicon fume and time while determining a fiber dispersant. It is essential for the uniform dispersion of carbon fibers at this stage. Good dispersion of carbon fibers in the pre-dispersion process can ensure the successful preparation of CFRC samples in the subsequent experiment.

However, this was the first step of fiber dispersion during the preparation of CFRC samples. Cement and other additives were not used, so it can only 

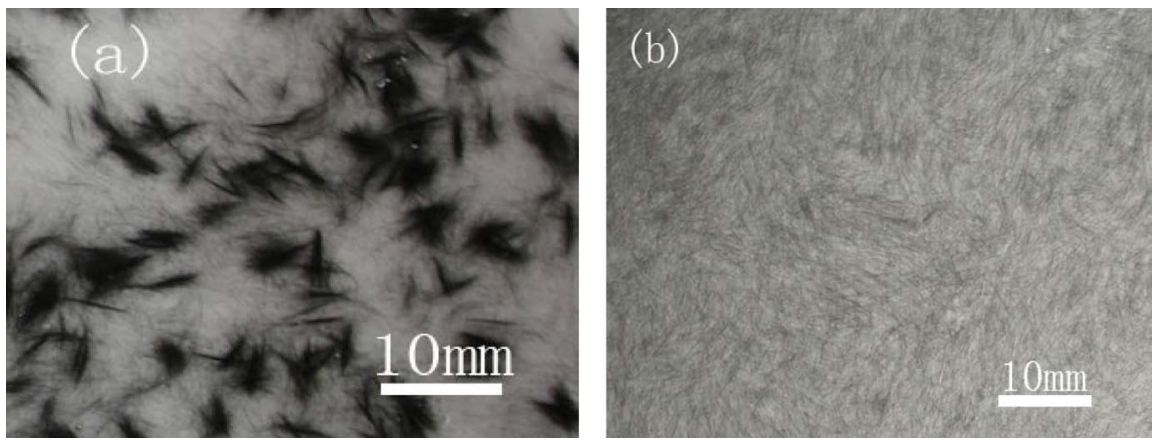

Figure 1. Comparison of dispersion degree of carbon fibers in water by digital photos. (a) Poor dispersion without HEC; (b) Good dispersion with HEC.

Table 2. Description of dispersion of carbon fibers by the SE method.

\begin{tabular}{cccc}
\hline Mixture & Initial state & $\begin{array}{c}\text { Add short fibers and } \\
\text { stir for } 3 \mathrm{~min}\end{array}$ & $\begin{array}{c}\text { Three minutes } \\
\text { after stirring }\end{array}$ \\
\hline $\begin{array}{c}\text { Water without } \\
\text { HEC }\end{array}$ & $\begin{array}{c}\text { Colorless and } \\
\text { transparent }\end{array}$ & $\begin{array}{c}\text { Single fiber and fasciculus } \\
\text { exists }\end{array}$ & $\begin{array}{c}\text { Fibers deposit at the } \\
\text { bottom of the beaker }\end{array}$ \\
Water with & Colorless and sticky & $\begin{array}{c}\text { Fibers exist almost single by } \\
\text { sEC }\end{array}$ & $\begin{array}{c}\text { Fingle } \\
\text { but disperse evenly }\end{array}$ \\
\hline
\end{tabular}

represent the fiber dispersion state in the liquid mixture before the preparation of CFRC and cannot reveal the actual dispersion degree in hardened CFRC because the later mixing and molding operations, which are involved in the secondstep dispersion of fibers, may change the dispersion degree more or less.

\subsection{SEM Method}

A $40 \times 40 \times 40 \mathrm{~mm}$ hardened sample was compressed under an 8871-typed hydraulic pressure movable test system. The fracture surface was observed by a JEOL JSM-6460 scanning electron microscope to see the fiber dispersion state. The results are shown in Figure 2. This method is intuitionistic and in point to analyze the dispersion of fibers in small area and is applicable for CFRC of any types. The result is actual but limited by the number of samples and the area of sampling. It can be seen clearly that there were many biggish pores in a specimen (Figure 2(b)) due to poor dispersion of carbon fibers. In comparison, the structure of the specimen looks compact when fibers were distributed uniformly (Figure 2(a)).

Obviously, carbon fibers were dispersed singly when they were well distributed but fasciculi appeared when they were not well dispersed. Good dispersion is closely related with the mechanical, electrical and electromagnetical properties of CFRC [2] [3] [15].

\subsection{FM Method}

Take some pieces of the mixture of about the same weight from different areas of 

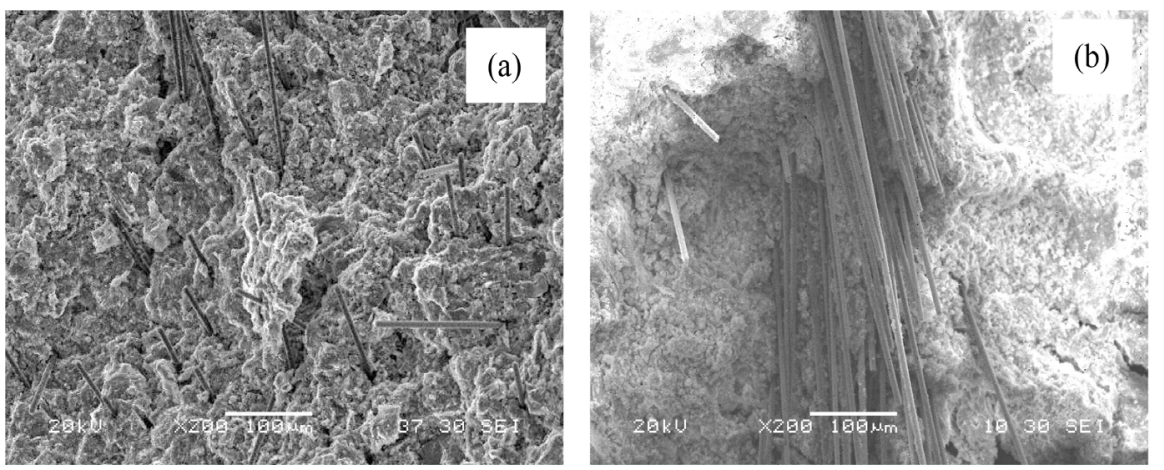

Figure 2. SEM images of carbon fiber dispersion in CFRC (mass fraction of carbon fibers $0.33 \mathrm{wt} \%$ by weight of cement). (a) Carbon fibers are well dispersed in the cement matrix and the specimen looks compact; (b) Carbon fibers are poorly dispersed in the cement matrix and the phenomenon of carbon fiber fasciculi can be seen clearly.

fresh CFRC samples, wash the fibers clean, dry up and weigh them, then calculate the mass of carbon fibers. The mass variation coefficient $\Phi_{m}$ is calculated in accordance with Formula (1):

$$
\Phi_{m}=\frac{\sqrt{\sum_{i=1}^{n}\left|X_{m i}-\bar{X}_{m}\right|^{2} /(n-1)}}{\bar{X}_{m}} \times 100 \%
$$

where $X_{m i}$ refers to the carbon fiber content of sample $i$ under test number $m$ (g/100g cement); $\bar{X}_{m}$ means the average fiber content separated from test number $m(\mathrm{~g} / 100 \mathrm{~g}$ cement); $n$ stands for the number of samples; $m$ is the test number; $\Phi_{m}$ indicates the variation coefficient. According to Equation (1), if carbon fibers are uniformly dispersed or $X_{m i}$ is the same (from $i=1$ to $i=n$ ), then $\Phi_{m}$ $=0$. If carbon fibers are in one sample only, then $\Phi_{m} \rightarrow \infty$. Therefore, $\Phi_{m}$ is always over zero at normal conditions. The less $\Phi_{m}$ is, the better dispersed the fibers are.

This method to comment on the dispersion of carbon fibers through the mass variation coefficient $\Phi_{m}$ is called as the fresh mixture (FM) method.

It is quick, simple and applicable to determine the dispersion of fibers in CFRC. It is useful to determine the applicable mixing process, but fails to suggest the fiber dispersion in any of the samples because the result is influenced by the number of samples and the weight of each sample. Additionally, the vibration time in later experiments may change the fiber dispersion more or less. Therefore, it cannot respond to the actual fiber dispersion in hardened CFRC samples.

\subsection{Measurement of Electrical Resistivity}

Series of specimens, each being a cubic size of $40 \mathrm{~mm} \times 40 \mathrm{~mm} \times 40 \mathrm{~mm}$, were prepared for the measurement of the electrical resistivity. The specimens were air-dried after 28-day curing. Then two copper electrodes were stuck on the opposite surface of each specimen by a graphite-conductive adhesive. The resistance was read directly by a DT9205A digital universal meter. The electrical re- 
sistivity $\rho$ and the variation coefficient $\Phi_{\Omega}$ of electrical resistivity were calculated in accordance with Equations (2), (3) and (4).

$$
\begin{gathered}
\rho=\frac{R S}{l} \\
\Phi_{\Omega}=\frac{\sqrt{\sum_{i=1}^{n}\left|\rho_{i}-\bar{\rho}\right|^{2} /(n-1)}}{\bar{\rho}} \times 100 \% \\
\bar{\rho}=\sum_{i=1}^{n} \rho_{i}
\end{gathered}
$$

where $R$ refers to the electrical resistance $(\mathrm{k} \Omega) ; S$ stands for the area of electrodes $\left(\mathrm{cm}^{2}\right) ; 1$ means the space between two electrodes of a specimen $(\mathrm{cm}) ; \rho_{i}$ indicates the electrical resistivity of the number $i$ specimen, $(\mu \Omega \cdot \mathrm{m}) ; \bar{\rho}$ is the average value of the electrical resistivity of specimens measured under the same condition; $n$ demonstrates the number of specimens measured in the same condition. The direct current was so small that the polarization could be negligible during measurement. The two- and four-probe methods gave the same results.

For specimens of the same fiber fraction, the best dispersion effect can be achieved when the electrical resistivity $\rho$ and the variation coefficient $\Phi_{\Omega}$ of the electrical resistivity are in the lowest values. This is because carbon fibers are more conductive than the hardened cement matrix [1] [2] [10]. When carbon fibers were distributed uniformly in the matrix, they overlapped each other to form a conductive network. In this case, CFRC is a good conductor of electricity. So, the values of $\rho$ and $\Phi_{\Omega}$ fall down to the minimum.

In case of carbon fibers at a volume fraction below the percolation threshold, the electrical conductivity of the composite is highly dependent on the degree of fiber dispersion. The greater the dispersion degree, the higher the conductivity. At the same time, the resistivity of CFRC is also sensitive to the air void content and the fiber-matrix interface. Although the electrical conductivity decreases with the increase of the air void content or the poor fiber-matrix interface structure, the variation coefficient must be low while the fibers are dispersed uniformly. On the contrary, if the variation coefficient is high, whether the electrical resistivity is high or not, a conclusion can be drawn that carbon fibers were not dispersed well in CFRC.

The result of ERM method provides a relative indication of dispersion degree of carbon fibers. It costs less than SEM analysis does. However, it cannot tell the actual dispersion of fibers in any of the specimens. Factors, such as the structure of cement paste, content and length of fibers, may lead to great changes of electrical resistivity. In addition, to determine the dispersion of carbon fibers influenced by mixing or molding, other factors must be changeless. So, the result by this way is not always reliable. If the true dispersion of fibers is required, whether it is macroscopically or microcosmically, this method may be used together with other methods. 


\section{Results and Discussion}

\subsection{Surface Modification of Carbon Fibers by CVD Treatment}

Figure 3 demonstrated the SEM images of the surface of carbon fibers after CVD processing. As seen in Figure 3(a), the surface of carbon fibers prior to treatment looks smooth. When they are added into cement substrate in this status, it can be concluded that the interracial adhesion between the fiber surface and cement is weaker due to smooth surface, the density of the CFRC composite is lower, and the strength of the composite is not good.

To improve the interfacial bonding between carbon fibers and cement matrix, carbon fibers were treated by CVD at high temperature. By controlling the gas flow rate and volume, an uneven layer of pyrocarbon deposited on the surface of carbon fibers. For comparison, after CVD processing, the surface of carbon fibers was rough as shown in Figure 3(b) owing to the uneven deposition of pyrocarbon. In this case, it can be expected that there is a good interface bonding force between the treated fiber surface and cement matrix because of larger surface area and surface grooves, both of which can lead to strong gripping forces between the matrix and the reinforcement [2] [16]. In addition, chemical groups such as hydroxyl and carbonyl might be removed at high temperature, which is conducive to the combination of fiber and cement [2] [4] [7]. Thus, in the subsequent study, CFRC of fine properties can be prepared.

CVD process involves the dissociation and chemical reactions of precursor gaseous reactants in a furnace [2] [13]. It is a complex chemical system which is influenced by thermodynamics, chemical kinetics and mass transport. The purpose of this treatment is to enhance the bond stress between the substrate and the reinforcement so as to eventually achieve good properties of CFRC composites.

\subsection{Effect of Dispersant HEC}

The dispersion degree of carbon fibers was validated by methods of SE, SEM, FM, and ERM, respectively. From the experiments above, some of the advantages and disadvantages of each method were basically evident. For further investigation, each method was discussed in details.
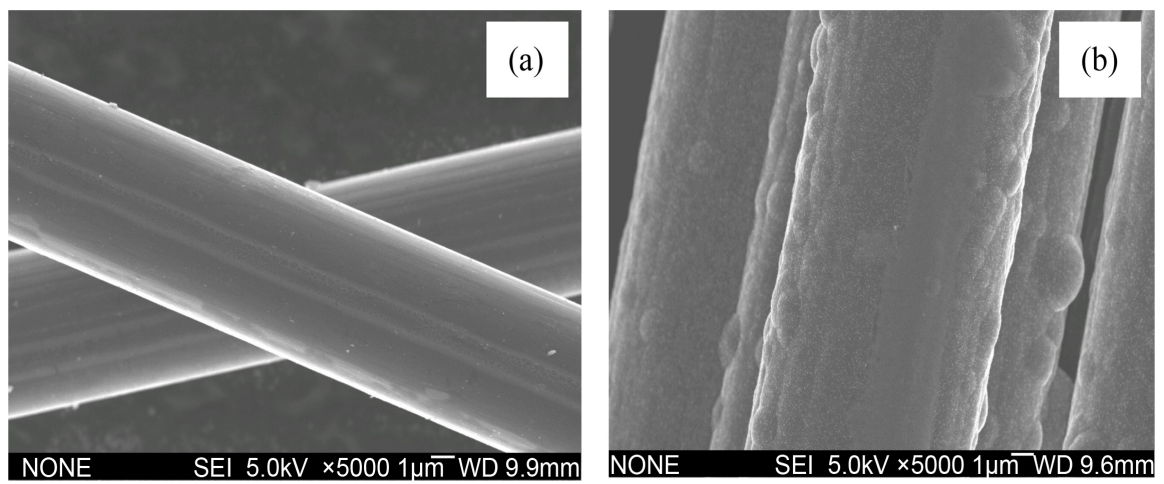

Figure 3. (a) Before CVD surface treatment; (b) After CVD surface treatment. 
The experimental results are intuitively demonstrated in Figure 2 by SE method. Carbon fibers were dispersed singly only in water containing HEC. This is because that HEC is not only a frequently used dispersant, but a kind of surface active agent. It can soak the surface of carbon fibers well and disperse them by single thread. In addition, HEC can avoid the assembling of carbon fibers by forming a layer of sticky film on the fiber surface. The fibers are wrapped, forming a relatively stable quasi-colloid system, which is mostly helpful for their further dispersion in the subsequent preparation of CFRC.

The SEM micrographs of the fracture surface of the later prepared CFRC samples indicated that in the pre-dispersion of carbon fibers, the appropriate mass fraction of HEC in the aqueous solution was around $1.80 \%$ and in the later dispersion, the proper mass fraction of HEC in the solid mixture was $0.66 \%$ by weight of cement. Under such a condition, carbon fibers are homogenized either in water prior to the preparation of CFRC or in the cement matrix during the course of preparation.

Figure 2 shows the SEM images of the fracture surface of hardened CFRC samples. In Figure 2(a), carbon fibers were uniformly distributed in the cement matrix. The structure was more compact and the fibers were well combined with the matrix. Accordingly, it can be inferred that the samples may possess good mechanical properties. Comparatively, there were numerous larger pores, holes or fasciculi when carbon fibers were not dispersed evenly in the matrix as shown in Figure 2(b). This poor dispersion may lead to the poor interface bonding between fibers and cement matrix. In fact, the dispersion degree is greatly responsible for the electrical resistivity of CFRC. The variation coefficient of electrical resistivity proved in turn that HEC can truly improve the dispersion degree [2] [11] [17]. SEM method is intuitional and in point to reflect the actual dispersion of fibers in small area and is also applicable for CFRC of any types, though it is costly. The result obtained by this method is actual but limited by the number of samples and the area of sampling. It cannot reflect the macroscopical distribution of fibers.

\subsection{Variation of Mass Variation Coefficient with Mixing Time}

Figure 4 shows the correlation between the mixing time and the mass variation coefficient of carbon fibers through the FM method. Obviously, the mass variation coefficient $\Phi_{m}$ was decreased in the first two minutes and increased in the later three minutes. Five minutes later, $\Phi_{m}$ was gradually declined again for each type of the mixture. As for any of the same mixing time, $\Phi_{m}$ in the mixture without HEC was always higher than that in the mixture with HEC.

The changes of the mass variation coefficient were divided into three stages. Carbon fibers first met water and mix, and fasciculi gradually dispersed such that $\Phi_{m}$ was reduced. With the mixing time proceeding, the relatively welldistributed carbon fibers started to gather together and fasciculate, resulting in the increasing of the variation coefficient. When the mixing time was too long, 


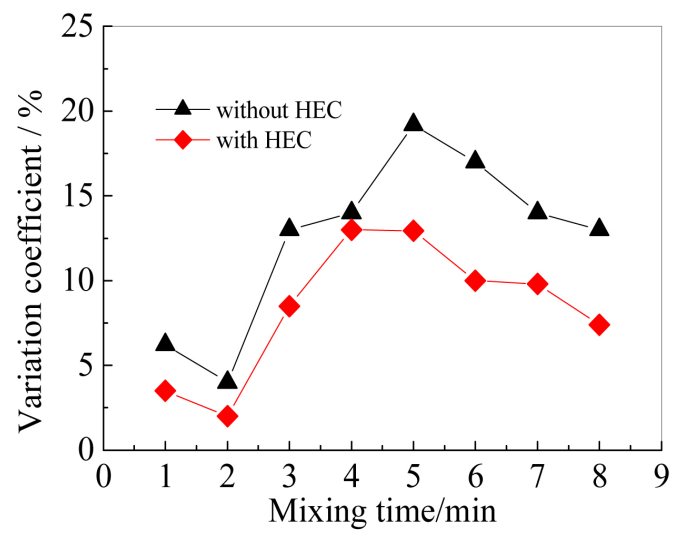

Figure 4. Correlation between the mixing time and mass variation coefficient of carbon fibers.

some of the fibers were finally broken and became shorter such that they were difficult to fasciculate hence the decreasing of $\Phi_{m}$. As a result, the distribution state of fibers gradually turned from fascicules into uniform state from the viewpoint of statistics. Two minutes was the best mixing time when all factors were taken into account. At this time, there was no breakage and wastage. The dispersion degree at this moment was most ideal. The mass variation coefficient curve implied that carbon fibers experienced the variation process of dispersion, conglomeration, breakage and a little better dispersion in the mixture [3] [11] [17] [18] [19]. Meanwhile, it suggested that HEC had really improved the dispersion degree of fibers.

\subsection{Variation of Variation Coefficient of Electrical Resistivity with Mixing Time}

Table 3 gives the results of ERM method. $S_{1}$ stands for samples without HEC while $S_{2}$ are those with HEC. For any of the conditions, the electrical resistivity of $S_{2}$ is higher than that of $S_{1}$ and the variation coefficient $\Phi_{\Omega}$ is lower than that of $S_{1}$, which suggests that HEC is helpful in improving the dispersion degree of carbon fibers. The fact that the electrical resistivity of $\mathrm{S}_{2}$ is higher than that of $\mathrm{S}_{1}$ may be attributed to the higher air content or the change of fiber-matrix interface resulting from the addition of HEC.

Figure 5 illustrates the relationship between the mixing time and the variation coefficient $\Phi_{\Omega}$ of the electrical resistivity. The variation coefficient was decreased abruptly in the first two minutes and then it slowed down gradually because carbon fibers dispersed more and more evenly with the mixing time proceeding. However, when the mixing time was over three minutes, the variation coefficient was increased slightly owing to some breakage of carbon fibers which in turn, to some extent, caused fasciculi in the matrix, leading further to the reduction of conductivity of the CFRC samples. That is why the curve was declined steeply in the first two minutes, fell down slowly, and rose gradually after the mixing time was over three minutes. 
Table 3. Results of measurement of electrical resistivity.

\begin{tabular}{ccccccc}
\hline & \multicolumn{2}{c}{ I } & \multicolumn{2}{c}{ II } & \multicolumn{2}{c}{ III } \\
\cline { 2 - 7 } & $\rho / \mathrm{k} \Omega \cdot \mathrm{cm}$ & $\Phi_{\Omega} / \%$ & $\rho / \mathrm{k} \Omega \cdot \mathrm{cm}$ & $\Phi_{\Omega} / \%$ & $\rho / \mathrm{k} \Omega \cdot \mathrm{cm}$ & $\Phi_{\Omega} / \%$ \\
\hline $\mathrm{S}_{1}$ & 15.05 & 82.4 & 8.45 & 126.3 & 7.2 & 62.3 \\
$\mathrm{~S}_{2}$ & 16.4 & 6.1 & 14.2 & 48.3 & 13.4 & 18.4 \\
\hline
\end{tabular}

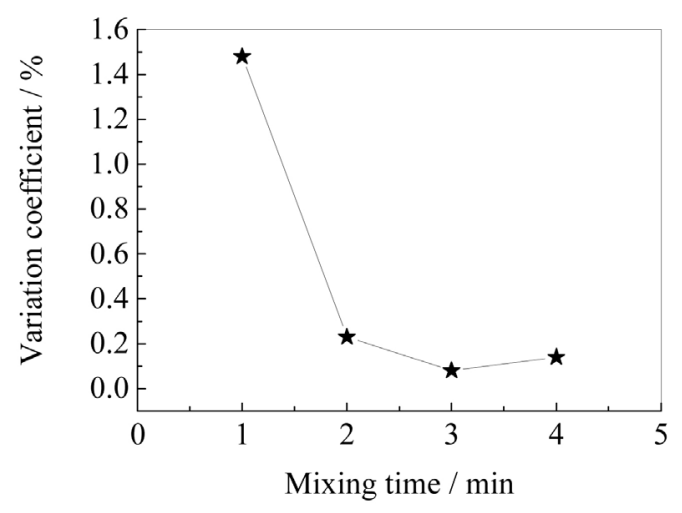

Figure 5. Correlation between the mixing time and variation coefficient of electrical resistivity.

\section{Conclusions}

1) Short carbon fibers were surface treated by CVD process at high temperature between $900^{\circ} \mathrm{C}$ and $1200^{\circ} \mathrm{C}$ under the protection of diluted nitrogen gas $\mathrm{N}_{2}$ to improve the surface activity of carbon fibers. An uneven layer of pyrocarbon was deposited, covering the fiber surface. The surface activity of carbon fibers was modified due to formed grooves and being removed chemical groups.

2) Four methods were introduced to assess the fiber dispersion degree either in the aqueous solution or in the cement matrix. SEM method reflected the actual micrograph of fiber dispersion in hardened CFRC composites for practical applications so that the mechanical and electrical performances may be predicted, though it is difficult to achieve some macrographic information of fiber dispersion state. FM method was quick to evaluate the fiber dispersion degree in different CFRC mixture and to conclude the damage degree of fibers during mixing of additives such that a reasonable mix process is provided, though it can only reflect the fiber dispersion degree prior to the formation of mixture. Compared with SEM method, ERM method was used to determine the fiber dispersion degree in different hardened CFRC samples, though it cannot reflect the microcosmic dispersion of fibers besides the less accurate result. SE method was the simplest way to assess the fiber dispersion state in the aqueous solution prior to the preparation of CFRC composites so that an appropriate dispersant can be chosen.

The best way should be selected in accordance with the actual preparation situation of CFRC or several methods may be used together to obtain the actual, accurate dispersion result. 


\section{Acknowledgements}

This work was financially supported by Shaanxi Province Engineering Laboratory of High Performance Concrete under the grant No. G2015-05 and Weinan Basic Research Innovation Talent Project with the grant No. 2015KYJ-3-3. The authors would like to thank Prof. Li Kezhi of Northwestern Polytechnical University for his experimental encouragement and support. The authors also express their sincere thanks to Dr Jiao Gengsheng of Weinan Teachers' University for his experimental assistance.

\section{References}

[1] Chung, D.D.L. (2000) Cement Reinforced with Short Carbon Fibers: A Multifunctional Material. Composites, Part B, 31, 511-526. https://doi.org/10.1016/S1359-8368(99)00071-2

[2] Li, K.Z., Wang, C., Li, H.J., Li, X.T., Ouyang, H.B. and Wei, J. (2008) Effect of Chemical Vapor Deposition Treatment of Carbon Fibers on the Reflectivity of Carbon Fiber-Reinforced Cement-Based Composites. Composites Science and Technology, 68, 1105-1114. https://doi.org/10.1016/j.compscitech.2007.08.003

[3] Wang, C., Li, K.Z., Li, H.J., Jiao, G.S., Lu, J.H. and Hou, D.S. (2008) Effect of Carbon Fiber Dispersion on the Mechanical Properties of Carbon Fiber-Reinforced Cement-Based Composites. Materials Science and Engineering: A, 487, 52-57. https://doi.org/10.1016/j.msea.2007.09.073

[4] Larson, B.K., Drzal, L.T. and Sorousian, P. (1990) Carbon Fiber-Cement Adhesion in Carbon Fiber-Reinforced Cement Composites. Composites, 21, 205-215. https://doi.org/10.1016/0010-4361(90)90235-O

[5] Yan, H., Sun, W. and Chen, H. (1999) Effect of Silica Fume and Steel Fiber on the Dynamic Mechanical Performance of High-Strength Concrete. Cement and Concrete Research, 29, 423-426. https://doi.org/10.1016/S0008-8846(98)00235-X

[6] Cao, J. and Chung, D.D.L. (2001) Improving the Dispersion of Steel Fibers in Cement Mortar by the Addition of Silane. Cement and Concrete Research, 31, 309311. https://doi.org/10.1016/S0008-8846(00)00470-1

[7] Sul, I.H., Youn, J.R. and Song, Y.S. (2011) Quantitative Dispersion Evaluation of Carbon Nanotubes Using a New Analysis Protocol. Carbon, 49, 1473-1478. https://doi.org/10.1016/j.carbon.2010.12.017

[8] Wang, Z.J., Gao, J., Ai, T., Jiang, W. and Zhao, P. (2014) Quantitative Evaluation of Carbon Fiber Dispersion in Cement Based Composites. Construction and Building Materials, 68, 26-30. https://doi.org/10.1016/j.conbuildmat.2014.06.035

[9] Anastasia, S., Viktor, M., Vyacheslav, K., Diana, M., Mandy, M., Manfred, R. and Albrecht, L. (2012) Dispersion of Carbon Nanotubes and Its Influence on the Mechanical Properties of the Cement Matrix. Cement and Concrete Composites, 34, 1104-1113. https://doi.org/10.1016/j.cemconcomp.2012.07.008

[10] Mao, Q.Z., Yang, Y.X., Li, Z.Q. and Shen, D.R. (1997) Effect of Additions on Electrical Conduction of CFRC. Journal of Inorganic Materials, 12, 415-419.

[11] Wang, Z.J., Li, K.Z. and Wang, C. (2014) Freezing-Thawing Effects on Electromagnetic Wave Reflectivity of Carbon Fiber Cement Based Composites. Construction and Building Materials, 64, 288-292. https://doi.org/10.1016/j.conbuildmat.2014.04.091

[12] Sobolkina, A., Mechtcherine, V., Khavrus, V., Maier, D., Mende, M., Ritschel, M. 
and Leonhardt, A. (2012) Dispersion of Carbon Nanotubes and Its Influence on the Mechanical Properties of the Cement Matrix. Cement and Concrete Composites, 34, 1104-1113. https://doi.org/10.1016/j.cemconcomp.2012.07.008

[13] Jin, Y.Z., Chen, J., Fu, Q.S., Li, B.H., Zhang, H.Z. and Gong, Y. (2015) Low- Temperature Synthesis and Characterization of Helical Carbon Fibers by One-Step Chemical Vapour Deposition. Applied Surface Science, 324, 438-442. https://doi.org/10.1016/j.apsusc.2014.10.107

[14] Song, M., Tang, X.H., Xu, J., Yu, L. and Wei, Y.X. (2016) The Formation of Novelcarbon/Carboncomposite by Chemical Vapor Deposition: An Efficient Adsorbent for Enhanced Desulfurization Performance. Journal of Analytical and Applied Pyrolysis, 11, 34-41. https://doi.org/10.1016/j.jaap.2015.12.020

[15] Sun, M.Q., Li, J., Wang, Y.J. and Zhang, X.Y. (2015) Preparation of Carbon Fiber Reinforced Cement-Based Composites Using Self-Made Carbon Fiber Mat. Construction and Building Materials, 79, 283-289.

https://doi.org/10.1016/j.conbuildmat.2015.01.060

[16] Greef, N.D., Zhang, L.M., Magrez, A., Forró, L., Locquet, J.P., Verpoest, I. and Seo, J.W. (2015) Direct Growth of Carbon Nanotubes on Carbon Fibers: Effect of the CVD Parameters on the Degradation of Mechanical Properties of Carbon Fibers. Diamond and Related Materials, 51, 39-48. https://doi.org/10.1016/j.diamond.2014.11.002

[17] Thakur, S.K.R., Mariamma, M. and Sharad, C.S. (2014) Exfoliation-Assisted Dispersion of Short Carbon Fibers in Silicon Carbide Powder. Powder Technology, 267, 273-278. https://doi.org/10.1016/j.powtec.2014.07.033

[18] Thakur, S.K.R. (2016) Effect of Milling Parameters on Exfoliation-Assisted Dispersion of Short Carbon Fibers in Silicon Carbide Powder. Advanced Powder Technology, 27, 145-153. https://doi.org/10.1016/j.apt.2015.11.015

[19] Parveen, S., Rana, S., Fangueiro, R. and Paiva, M.C. (2015) Microstructure and Mechanical Properties of Carbon Nanotube Reinforced Cementitious Composites Developed Using a Novel Dispersion Technique. Cement and Concrete Research, 73, 215-227. https://doi.org/10.1016/j.cemconres.2015.03.006

\section{Scientific Research Publishing}

\section{Submit or recommend next manuscript to SCIRP and we will provide best service for you:}

Accepting pre-submission inquiries through Email, Facebook, LinkedIn, Twitter, etc. A wide selection of journals (inclusive of 9 subjects, more than 200 journals)

Providing 24-hour high-quality service

User-friendly online submission system

Fair and swift peer-review system

Efficient typesetting and proofreading procedure

Display of the result of downloads and visits, as well as the number of cited articles

Maximum dissemination of your research work

Submit your manuscript at: http://papersubmission.scirp.org/

Or contact msa@scirp.org 